$\xi=-1$

\title{
Evaluation and Analysis of Available Transfer Capability in Deregulated Power System Environment
}

\author{
M. Dhana Sai Sri ${ }^{1 *}$, P. Srinivasa Varma ${ }^{2}$ \\ ${ }^{1}$ M.Tech student, Department of Electrical and Electronics Engineering ,KLEF, Vaddeswaram, Guntur,A.P,India. \\ ${ }^{2}$ Professor,Department of Electrical and Electronics Engineering, KLEF, Vaddeswaram, Guntur,A.P,India \\ *Corresponding author E-mail: dhanasaisrim@gmail.com
}

\begin{abstract}
Reliability of network is need of the hour in the present power system market and is constrained by capability of the network. The network calculations are performed using accurate and high efficient strategies. In order to perform power transactions in the system, the computation of available transfer capability is essential which a metric of capability of the system. Generally, effect wattless power is not taken into account in the methodologies for computation of linear available transfer capability. In this paper, a methodology which considers the reactive power flows for enhancement of linear ATC is presented. In order to perform analysis theoretically, a standard IEEE 3 bus system is considered. Another case study i.e., 14 bus system available in IEEE test systems is used for simulation analysis. FACTS technology is incorporated in the existing system in order to enhance capability of the network. To facilitate transfer maximum power in the system, an optimal power-flow-based ATC enhancement model is formulated and presented along with simulation results. Studies based on the IEEE 3-bus system and 14-bus systems with TCSC demonstrate the effectiveness of FACTS control on ATC enhancement.
\end{abstract}

Keywords: Available Transfer Capability; FACTS Technology; Network Capability; Optimal Power Flow; Transmission.

\section{Introduction}

Electricity trade is increased by manifold in the era of globalization. The lack of competition of the traditional power system markets is the basis for the restructuring process of the market. This calls for the accurate and reliable information about the generation limits and capabilities, the inherent power transmission range and capacity of the system. In electricity market, the utilities tend to facilitate transaction services to the bulk customers and Available Transfer Capacity (ATC) data should be available for this purpose. The transmission services are handled by monitoring the data . This is benefit and boon for advertisers, merchants and purchasers. Different specialists and researchers have done extensive study on ATC and other aspects. The ATC calculations on the sample IEEE 24 bus system is demonstrated in literature [1-5]. This proposed method is based on the assumptions in the DC power flow model and hence it results in poor accuracy and coherence. AC power transfer distribution factors(ACPTDF) based ATC calculation model is proposed by the scholars in this field. The determination of power flow solution of the system which the optimal solution is the pre ATC calculation procedure. The combined economic dispatch with the proper constraints is solved mathematically with the help of co ordination equations which are used to develop a technique for determination of ATC[6-12].

The restructuring of the electricity market is done by extensive power trading which increases the competition of the electricity market. The increase of the power transfer capability is the main goal in the opening of the power system environment under deregulated mode. The security and minimization of cost of opera- tion is the main goal of the electricity market environment despite numerous constraints and issues.

The alternatives of the power system operation are restricted by the creation of new facilities to minimize the financial, social and environmental based problems. The better quality of service to the customer at the convenient price which the customer does not feel burden is the main motto[3-8].

The general limits that exist for the transmission power transfer capability are stability, thermal and voltage limits. The FACTS technology changed the facet of power transmission system and widened the power transferability constraints. The case study based approach is choosen in this paper to study the effect of incorporation of FACTS devices in the system and demonstrate its effect on the ATC calculations. It is proposed that the placement of TCSC in the system will recover the ATC of the system. The power transfer capability will be enhanced by installing TCSC in the transmission system[6-10].

\section{Available Transfer Capability}

The availability of quality of electric power is the major issue in the first world nations to a minimum extent and to a maximum extent in the second world nations like India, Sri Lanka. The shortage of electric generation leads to shedding of the customers load in order to balance the supply demand considerations. The drastic mismatch between the customers demand and system supply leads to the consequences which are highly undesirable and undermines the trust of the utilities in view of the customers. The continuous monitoring of the power supply and demand is undertaken by the system operator to determine the instant power flow at any point of time provided the information regarding the current 
state and status of the system parameters are known. Available transfer capacity is an important concept in the power system operating deregulated mode about which the seller as well as buyer must be completely aware and agreeable on a mutual consent basis.

The system operator with a view to supply power reliably needs to know about the capacity of power available for transfer at any moment of time and under all system states. In a deregulated system operation, both the operator and the customers must be knowledgeable about this important system variable known as ATC.The secure operation of the system must be ensured while the transmission network is employed for the purpose of evaluation of available transfer capacit. The competition among the various utilities for market occupancy along with maximization of the dependability of the system is the driving factor for the growing prominence of ATC calculations. Improving ATC impacts the system in the following manner,

i. Reliable delivery of the supply to the customers.

ii. Flexible operation of the system along with variation in the conditions of the system

iii. Significant reduction in the installed capacity of generation, increasing the power limits

iv. Provides transaction rights with sellers and buyers.

Mathematically, ATC is defined as the Total Transfer Capability (TTC) excluding the Transmission Reliability Margin (TRM), excluding the sum of existing transmission commitments (which includes retail customer service) and the Capacity Benefit Margin (CBM). ATC can be expressed as [1] follows:

ATC $=$ TTC-TRM - Existing Transmission Commitments (including $\mathrm{CBM}$ ).

\subsection{Linear ATC}

The base case solution in the case of linear ATC is DC power flow solution. The basic assumption regarding this method the system under study is taken as without losses. The resultant active power insertion are varying linearly with flow of branch active power. In this section, without exceeding the line constraints the power transfer capability is altered. The type of transfer considered in this case is the power flow from slack bus s to arbitrary bus $i$ at any instant of time. In this paper, the ATC calculations are performed without considering the reactive power component while computation of system power flow.

\section{Power Shift Distribution Factor (PSDF):}

PSDF distributes the power flow to every branch in proportion to the fraction of the MW power flow transmitted during each transaction. In this way PSDF is utilized during the norms of computation of ATC. While power is transferred from s to i, the power fluctuation in the line $\mathrm{j}-\mathrm{k}$ is predicted and they are represented by huge difference sensitivities for instance in this paper. The linear connection among the transaction and flow of active power between buses in the transmission network is given a coefficient called as PSDF. In the transmission network, PSDF is the part of transaction between the buses.

The PSDF can be formulated as:

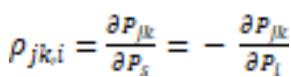

$\rho_{\text {jki }}=$ PSDF

$\partial P_{j k}=$ Power flow variation in line $\mathrm{j}-\mathrm{k}$

$\partial P_{s}=$ Power injected from bus 's'

$\partial P_{i}=$ Power injected to bus ' $i$

\subsection{Computation of LATC}

The Linear ATC (LATC) can be obtained by
$L A T C_{g \rightarrow i}=\min \left\{\Delta P_{g}^{j k}\right.$ all lines $\left.j k\right\}$

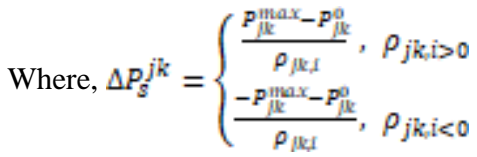

The complex power between $\mathrm{J}-\mathrm{K}$ buses can be given by

$S_{j k}=P_{j k}+j Q_{j k}$

Where, the real and reactive power terms in the eq. (4) can be separated as:

$P_{j k}-V_{j}^{2} G_{j k}=-V_{j} V_{k} Y_{j k} \cos \left(\theta_{j}-\theta_{k}+\alpha_{j k}\right)$

$Q_{j k}+V_{j}^{2} B_{j j}+V_{j}^{2} B_{j k}=-V_{j} V_{k} Y_{j k} \sin \left(\theta_{j}-\theta_{k}+\alpha_{j k}\right)$

By applying the square on both sides and adding to the eq. (6) becomes

$$
\begin{aligned}
& \left(P_{j k}-V_{j}^{2} G_{j k}\right)^{2}+\left(Q_{j k}+V_{j}^{2} B_{j j}+V_{j}^{2} B_{j k}\right)^{2}=\left(V_{j} V_{k} Y_{j k}\right)^{2} \\
& \left(P_{j k \emptyset}, Q_{j k \emptyset}\right)=\left(V_{j}^{2} G_{j k}-V_{j}^{2} B_{j j}-V_{j}^{2} B_{j k}\right) \\
& S_{j k \emptyset}=V_{j} V_{k} Y_{j h \odot}
\end{aligned}
$$

By substituting the eqs. (8) \& (9) in eq. (7), it is obtained as:

$\left(P_{j k}-P_{j k \emptyset}\right)^{2}+\left(Q_{j k}-Q_{j k @}\right)^{2}=S_{j k \emptyset}^{2}$

The above equation represents the complex flow at bus $\mathrm{j}$ and the complex flow at bus $\mathrm{k}$ is formulated as:

$$
\left(P_{k j}-P_{k j \sigma}\right)^{2}+\left(Q_{k j}-Q_{k j 0}\right)^{2}=S_{k j \odot}^{2}
$$

\subsection{Inclusion of Reactive Power Flows (ELATC)}

The procedure for finding $P_{j k}^{*}$ and $Q_{j k}^{*}$ is as:

$P_{j k}^{2}+Q_{j k}^{2}=\left(S_{j k}^{\max }\right)^{2}$

By expanding the eq. (10) and subtracting eq. (12) from that, it is obtained as:

$Q_{j k}=\frac{1}{2 Q_{j 09}}\left(-2 P_{j k} P_{j k \odot}+\left(S_{j k}^{\max }\right)^{2}-M^{2}\right)$

Where, $M^{2}=S_{j k @}^{2}-P_{j k \emptyset}^{2}-Q_{j k \emptyset}^{2}$

By substituting eq. (13) in eq. (12), the quadratic equation in terms of $P_{j k}^{i}$ is obtained as:

$$
\begin{aligned}
& \left(P_{j k @}^{2}-Q_{j k \emptyset}^{2}\right) P_{j k @}^{22}-P_{j k @}\left(\left(S_{j k}^{\max }\right)^{2}-M^{2}\right) P_{j k \emptyset}^{22}+ \\
& \frac{1}{4}\left(\left(S_{j k}^{\max }\right)^{2}-M^{2}\right)^{2}-Q_{j k \emptyset}^{2}\left(S_{j k}^{\max }\right)^{2}=0
\end{aligned}
$$

Now, the maximum complex power flow solution is attained as

$$
\begin{aligned}
& P_{j k}^{i}=\frac{-b \pm \sqrt{b^{2}-4 a c}}{2 a} \\
& Q_{j k}^{i}=\sqrt{\left(s_{j k}^{\max }\right)^{2}-P_{j k 0}^{22}}
\end{aligned}
$$

Where,

$a=\left(P_{j k Q}^{2}-Q_{j k Q}^{2}\right)$ 


$$
\begin{aligned}
& b=-P_{j k \sigma}\left(\left(S_{j k}^{\max }\right)^{2}-M^{2}\right) \\
& c=\frac{1}{4}\left(\left(S_{j k}^{\max }\right)^{2}-M^{2}\right)^{2}-Q_{j k \emptyset}^{2}\left(S_{j k}^{\max }\right)^{2}
\end{aligned}
$$

The enhanced linear ATC can be calculated by taking the minimum value of $\Delta P_{\mathscr{S}}^{j k s}$ as:

$$
E L A T C_{g \rightarrow i}=\min \left\{\Delta P_{\mathscr{B}}^{j k s} \text { a all lines } j k\right\}
$$

\section{Effect of FACTS Controllers on ATC Cal- culations}

FACTS controllers has the capacity to control the reliable parameters that oversee the activity of transmission framework including impedance connected in series, admittance connected in shunt, current, voltage, phase angle and damping. To determine the framework issues in the late 1980s, the Electric Power Research Institute (EPRI) recommended that other than adaptable powerstream control over assigned transmission structures, another real goal of FACTS applications is to build the power-exchange ability of transmission frameworks [4]. By the control of line reactance and phase angle of the voltage, FACTS innovation empowers the stamina of power delivery of the transmission lines. In this way, hypothetically it can offer a successful and promising contrasting option to regular strategies for ATC upgrade. The FACTS controllers are demonstrated by the parameters, for example, compensation method in series for TCSC and Susceptance for SVC [12].

An ideal power-flow - based ATC is planned to accomplish the power exchange of the predefined interface with FACTS control Based on the technique proposed for enhancing ATC by the control of UPFC in [12], this paper centers around quantitative assessment of the effect of FACTS gadgets on ATC. At last, with the IEEE 3-transport framework and 14-transport framework as a testing framework, simulation studies are performed on a class of FACTS gadgets. The outcomes show the efficiency of FACTS control on ATC improvement.

TCSC involve controlled reactors in parallel with divisions of a capacitor bank. This combination allows plane control of the fundamental frequency capacitive reactance over a wide array. The capacitor bank of each phase is attached on a platform to assist full insulation to ground. The thyristor regulator contains a string of series connected high control thyristors. The inductor is of air-core design. A metal oxide varistor (MOV) is connected across the capacitor to avoid overvoltage. The figure shows the thyristor control series compensation.

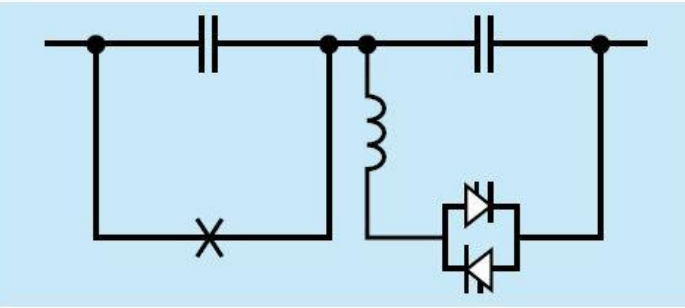

Fig 1: Thyristor Controlled Series Compensation

TCSC involves in important major applications in series which are

a) Damping of active power oscillations

b) Power flow control

c) Stability improvement

d) Elimination of resonance

TCSC which carries the capacitor in series with typical values

TCSC uses for optimization of power flow from one region to another region for power supply it and power control flows b) Eliminating line over loads

c) Optimal load sharing between two parallel circuits

d) Power flow along contractual path

This system represents the 3- bus and 14-bus data by using power world simulator

\section{Results of Simulation}

\subsection{IEEE 3-Bus System}

The simulation results for test 3 bus framework from MATLAB program are exhibited in this area. The examination of the outcomes is likewise as predicted about in this area. The estimations of line constraint, PTDF and LATC without wattless power when bus 2 is utilized as dealer and bus 3 is utilized as purchaser are exhibited in the Table 1. In this, line 3 is the constraining line and the LATC is $170.02 \mathrm{MW}$. The estimations of line farthest point, PSDF and ELATC with reactive power when bus 2 is utilized as merchant and bus 3 is utilized as purchaser are displayed in the Table 2 . In this additionally, line 3 is the restricting line and the ELATC is $162.95 \mathrm{MW}$

Table 1 LATC result for sample 3 bus system

\begin{tabular}{|l|l|l|l|l|}
\hline $\begin{array}{l}\text { Branch } \\
\text { number }\end{array}$ & $\begin{array}{l}\text { Branch } \\
\text { Flow(MW) }\end{array}$ & $\begin{array}{l}\text { Line } \\
\text { Limit(MW) }\end{array}$ & PTDF & LATC(MW) \\
\hline 1 & 0.00 & -100.00 & -0.18 & 566.43 \\
\hline 2 & 0.00 & 130.00 & 0.18 & 736.36 \\
\hline 3 & 0.00 & 140.00 & 0.82 & 170.02 \\
\hline
\end{tabular}

Table2 ELATC result for sample 3 bus system

\begin{tabular}{|l|l|l|l|l|}
\hline $\begin{array}{l}\text { Branch } \\
\text { number }\end{array}$ & $\begin{array}{l}\text { Branch } \\
\text { Flow(MW) }\end{array}$ & $\begin{array}{l}\text { Line } \\
\text { Limit(MW) }\end{array}$ & PTDF & LATC(MW) \\
\hline 1 & 0.00 & -100.00 & -0.18 & 566.43 \\
\hline 2 & 0.00 & 130.00 & 0.18 & 736.36 \\
\hline 3 & 0.00 & 134.18 & 0.82 & 162.95 \\
\hline
\end{tabular}

Hence, it is concluded that, the ATC value with reactive power flows is very near to the actual ATC with less error. This reduction in error represents the benefit from ELATC.

The ATC calculations are also performed for IEEE 3 bus system with and without incorporation of FACTS controller, TCSC.

Table 3 result for 3 Bus system Without facts device:

\begin{tabular}{|l|l|l|l|l|l|}
\hline $\begin{array}{l}\text { SI } \\
\text { NO }\end{array}$ & $\begin{array}{l}\text { Transmission } \\
\text { Limit (MW) }\end{array}$ & $\begin{array}{l}\text { Limiting } \\
\text { element }\end{array}$ & $\begin{array}{l}\% \\
\text { OTDF }\end{array}$ & $\begin{array}{l}\text { Pre- } \\
\text { transmission } \\
\text { estimation }\end{array}$ & $\begin{array}{l}\text { Limit } \\
\text { used }\end{array}$ \\
\hline 1 & 0.00 & Area 2(2) & 0.00 & 0.00 & 0.00 \\
\hline 2 & 170.87 & $\begin{array}{l}\text { Line 2(2) } \\
\text { to 3(3) }\end{array}$ & 81.94 & -0.00 & 140 \\
\hline 3 & 553.57 & $\begin{array}{l}\text { Line 1(1) } \\
\text { to 2(2) }\end{array}$ & -18.06 & -0.00 & -100 \\
\hline 4 & 719.64 & $\begin{array}{l}\text { Line 1(1) } \\
\text { to 3(3) }\end{array}$ & 18.06 & 0.00 & 130.00 \\
\hline 5 & 800 & Area 3(3) & 0.00 & 0.00 & 0.00 \\
\hline
\end{tabular}

Table 4 result for 3 bus system with FACTS:

\begin{tabular}{|l|l|l|l|l|l|}
\hline $\begin{array}{l}\text { SI } \\
\text { NO }\end{array}$ & $\begin{array}{l}\text { Transmission } \\
\text { Limit (MW) }\end{array}$ & $\begin{array}{l}\text { Limiting } \\
\text { element }\end{array}$ & $\begin{array}{l}\% \\
\text { OTDF }\end{array}$ & $\begin{array}{l}\text { Pre- } \\
\text { transmission } \\
\text { estimation }\end{array}$ & $\begin{array}{l}\text { Limit } \\
\text { used }\end{array}$ \\
\hline 1 & 0.00 & Area 2(2) & 0.00 & 0.00 & 0.00 \\
\hline 2 & 169.76 & $\begin{array}{l}\text { Line 2(2) } \\
\text { to 3(3) }\end{array}$ & 82.47 & -0.00 & 140 \\
\hline 3 & 570.37 & $\begin{array}{l}\text { Line 1(1) } \\
\text { to 2(2) }\end{array}$ & -17.53 & -0.00 & -100 \\
\hline 4 & 741.48 & $\begin{array}{l}\text { Line 1(1) } \\
\text { to 3(3) }\end{array}$ & 17.53 & 0.00 & 130.00 \\
\hline 5 & 800 & Area 3(3) & 0.00 & 0.00 & 0.00 \\
\hline
\end{tabular}

\subsection{IEEE 14-bus System}

In this section, the results obtained for LATC and ELATC from simulation environment using IEEE 14 bus system are presented. The values of line limit, PTDF and LATC without reactive power 
when bus 6 is used as seller bus and bus 8 is used as buyer bus are presented in the Table 5. In this, line 8 is the limiting line and the LATC is $363.92 \mathrm{MW}$.

Table 5 LATC result for IEEE 14 bus

\begin{tabular}{|l|l|l|l|l|}
\hline $\begin{array}{l}\text { Branch } \\
\text { Number }\end{array}$ & $\begin{array}{l}\text { Branch } \\
\text { Flow(MW) }\end{array}$ & $\begin{array}{l}\text { Line } \\
\text { Limit(MW) }\end{array}$ & PTDF & $\begin{array}{l}\text { LATC } \\
\text { MW }\end{array}$ \\
\hline 1 & -69.80 & 175 & 0.07 & 325400.68 \\
\hline 2 & 15.30 & -175 & -0.01 & 3343326 \\
\hline 3 & 67.78 & 175 & 0.03 & 3261.32 \\
\hline 4 & 51.37 & 175 & 0.07 & 1754.64 \\
\hline 5 & 42.05 & -175 & -0.03 & 6955.42 \\
\hline 6 & -26.42 & 175 & 0.03 & 6126.78 \\
\hline 7 & -35.07 & -400 & -0.41 & 882.48 \\
\hline 8 & 7.74 & 175 & 0.46 & 363.92 \\
\hline 9 & 4.48 & 175 & 0.06 & 2978.24 \\
\hline 10 & 15.69 & -175 & -0.45 & 423.20 \\
\hline 11 & 3.97 & 175 & 0.32 & 541.25 \\
\hline 12 & 2.20 & 175 & 0.05 & 3326.76 \\
\hline 13 & -1.67 & 175 & 0.18 & 973.52 \\
\hline 14 & -0.00 & 400 & 1.00 & 400 \\
\hline 15 & 7.74 & -400 & -0.54 & 754.55 \\
\hline 16 & 8.53 & -400 & -0.32 & 1292.84 \\
\hline 17 & -25.81 & -400 & -0.17 & 2239.06 \\
\hline 18 & -0.47 & -500 & -0.32 & 1580.82 \\
\hline
\end{tabular}

The values of line limit, PTDF and LATC without reactive power when bus 6 is used as seller bus and bus 8 is used as buyer bus are presented in the Table 6 . In this, line 8 is the limiting line and the LATC is $359.74 \mathrm{MW}$.

Table 6 ELATC result for IEEE 14 bus system

\begin{tabular}{|l|l|l|l|l|}
\hline \multicolumn{5}{|l}{ Table 6 ELATC result for IEEE 14 bus system } \\
\hline $\begin{array}{l}\text { Branch } \\
\text { number }\end{array}$ & $\begin{array}{l}\text { Branch } \\
\text { Flow(MW) }\end{array}$ & $\begin{array}{l}\text { Line } \\
\text { Limit(MW) }\end{array}$ & PTDF & $\begin{array}{l}\text { ELATC } \\
\text { MW }\end{array}$ \\
\hline 1 & -69.80 & 175.00 & 0.07 & 325400.68 \\
\hline 2 & 15.30 & -175.00 & -0.01 & 3343326 \\
\hline 3 & 67.78 & 175.00 & 0.03 & 3261.32 \\
\hline 4 & 51.37 & 175.00 & 0.07 & 1754.64 \\
\hline 5 & 42.05 & -175.00 & -0.03 & 6955.42 \\
\hline 6 & -26.42 & 175.00 & 0.03 & 6126.78 \\
\hline 7 & -35.07 & -400.00 & -0.41 & 882.48 \\
\hline 8 & 7.74 & 173.08 & 0.46 & 359.74 \\
\hline 9 & 4.48 & 175.00 & 0.06 & 2978.24 \\
\hline 10 & 15.69 & -175.00 & -0.45 & 423.20 \\
\hline 11 & 3.97 & 175.00 & 0.32 & 541.25 \\
\hline 12 & 2.20 & 175.00 & 0.05 & 3326.76 \\
\hline 13 & -1.67 & 175.00 & 0.18 & 973.52 \\
\hline 14 & -0.00 & 400.00 & 1.00 & 400 \\
\hline 15 & 7.74 & -400.00 & -0.54 & 754.55 \\
\hline 16 & 8.53 & -400.00 & -0.32 & 1292.84 \\
\hline 17 & -25.81 & -400.00 & -0.17 & 2239.06 \\
\hline 18 & -0.47 & -500.00 & -0.32 & 1580.82 \\
\hline
\end{tabular}

The ATC calculations are also performed for IEEE 14 bus system with and without incorporation of FACTS controller, TCSC. Table 9 presents the comparison of error obtained with and without FACTS devices.

Table 7 result for IEEE 14 bus system without facts;

\begin{tabular}{|l|l|l|l|l|l|}
\hline $\begin{array}{l}\text { SI } \\
\text { NO }\end{array}$ & $\begin{array}{l}\text { Transmission } \\
\text { Limit (MW) }\end{array}$ & $\begin{array}{l}\text { Limiting } \\
\text { element }\end{array}$ & $\begin{array}{l}\% \\
\text { OTDF }\end{array}$ & $\begin{array}{l}\text { Pre- } \\
\text { transmission } \\
\text { estimation }\end{array}$ & $\begin{array}{l}\text { Limit } \\
\text { used }\end{array}$ \\
\hline 1 & 354.64 & $\begin{array}{l}\text { Line 4(4) } \\
\text { to 7(7) }\end{array}$ & 42.68 & 23.66 & 175 \\
\hline 2 & 446.24 & $\begin{array}{l}\text { Line 5(5) } \\
\text { to 6(6) }\end{array}$ & -47.14 & 35.34 & -175 \\
\hline 3 & 531.63 & $\begin{array}{l}\text { Line 6(6) } \\
\text { to 11(11) }\end{array}$ & 31.86 & 5.01 & 175 \\
\hline 4 & 400.00 & $\begin{array}{l}\text { Line 7(7) } \\
\text { to 8(8) }\end{array}$ & 100.00 & 0.00 & 400 \\
\hline 5 & 739.04 & $\begin{array}{l}\text { Line 7(7) } \\
\text { to 9(9) }\end{array}$ & -57.32 & 23.66 & -400 \\
\hline
\end{tabular}

2] Gabriel Ejebe, C., James Waight, G., Manuel SantosNieto, \& William Tinney, F (2000). Fast Calculation of Linear Available Transfer Capability. IEEE Trans. on Power Systems, Vol. 15(3), pp. 1112-1116.

[3] Santiago Grijalva, Peter W., Sauer, \& James D., Weber (2003). Enhancement of Linear ATC Calculations by the Incorporation of Reactive Power Flows. IEEE Trans. on Power Systems, Vol. 18(2), pp. 619-624.

[4] Azhar B., Khairuddin, S., Shahnawaz Ahmed, M., Wazir Mustafa, Abdullah, A., Mohd., Zin \& Hussein Ahmad (2004). A Novel Method for ATC Computations in a LargeScale Power System. IEEE Trans. on Power Systems, Vol. 19(2), pp. 1150-1158.

A., Rajabi-Ghahnavieh, M., Fotuhi-Firuzabad, Mohammad Shahidehpour \& R., Feuillet (2009). Optimal Allocation of Available Transfer Capability in Operating Horizon. IEEE Trans. on Power Systems, Vol. 24(2), pp. 967-975.

[6] R., Srinu Naik, Prof. K., Vaisakh \& K. (2010), Anand. Determination of ATC with PTDF using Linear Methods in Presence of TCSC. IEEE Conf., Vol. 5, pp. 146-151. 
[7] Yajing Gao, Zhi Wang \& Haifeng Liang (2012). Available Transfer Capability Calculation with Large Offshore Wind Farms Connected by VSC-HVDC. IEEE, PESISGT, pp. 1-6.

[8] S., Nagalakshmi, S., Kalyani, V., Alamelu Shobana, R., Naga Ranjeni \& P., Deepamangai (2012). Estimation of Available Transfer Capability under normal and contingency conditions in Deregulated Electricity Market. IEEE- International Conference on Advances in Engineering, Science and Management, pp. 453-459.

[9] Luo Gang, Chen Jinfu, Cai Defu, Shi Dongyuan \& Duan Xianzhong (2013). Probabilistic assessment of available transfer capability considering spatial correlation in wind power integrated system. IET Generation, Transmission \& Distribution, pp. 1527-1535.

[10] Nur Ashida Salim, Muhammad Murtadha Othman, Mohd Salleh Serwan \& Mahmud Fotuhi-Firuzabad (2013). Determination of available transfer capability with implication of cascading collapse uncertainty. IET Generation, Transmission \& Distribution, pp. 705715.

[11] Xin Fang, Fangxing Li and Ningchao Gao (2014). Probabilistic Available Transfer Capability Evaluation for Power Systems Including High Penetration of Wind Power. PMAPS, IEEE Conference, pp. 1-6.

[12] James A., Momoh and S., Surender Reddy (2014). Optimal Location of FACTS for ATC Enhancement. IEEE Conference, pp. 1-5. 